\title{
Investigation of Binary Mixtures Containing 1-Ethyl-3- methylimidazolium Bis(trifluoromethanesulfonyl)azanide and Ethylene Carbonate
}

\author{
Andreas Hofmann, ${ }^{*}{ }^{\dagger}$ Matthias Migeot, ${ }^{\dagger}$ and Thomas Hanemann ${ }^{\dagger,}$ \\ ${ }^{\dagger}$ Karlsruher Institut für Technologie (KIT), Institut für Angewandte Materialien-Werkstoffkunde (IAM-WK), \\ Hermann-von-Helmholtz-Platz 1, 76344 Eggenstein-Leopoldshafen, Germany \\ ${ }^{\ddagger}$ Universität Freiburg, Institut für Mikrosystemtechnik, Georges-Köhler-Allee 102, 79110 Freiburg, Germany
}

Supporting Information

\begin{abstract}
Temperature dependent viscosity, conductivity, and density data of binary mixtures containing ethylene carbonate (EC) and 1-ethyl-3-methylimidazolium bis(trifluoromethanesulfonyl)azanide (EMIM-TFSA) were determined at atmospheric pressure in a wide temperature range of (20 to 120) ${ }^{\circ} \mathrm{C}$. Additionally, differential scanning calorimetry (DSC) measurements were performed from $(-120$ to +100$){ }^{\circ} \mathrm{C}$ to characterize phase behavior of the mixtures. On the basis of the experimental data it is demonstrated that the lattice hole theory can be applied excellently to the conductivity data of the binary mixture EMIM-TFSA/EC. The viscosity data were fitted

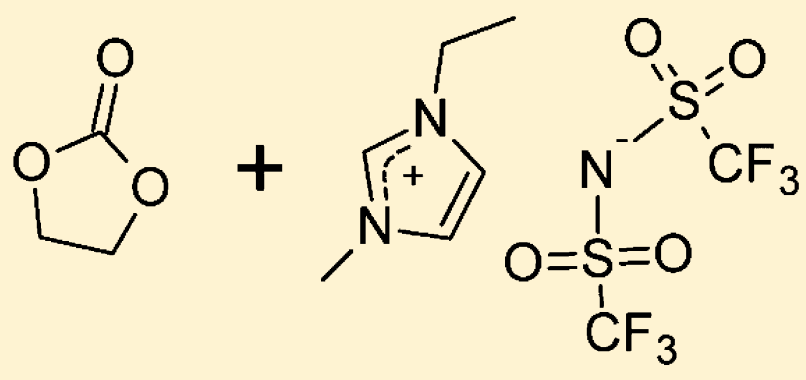
according to the Vogel-Fulcher-Tammann-Hesse (VFTH) equation and analyzed with the help of the fractional Walden rule. It is concluded that the mixtures can be classified as fragile according to ionicity. The aim of the study is to present fundamental physicochemical data about the mixtures as a basis for structure-property relationship-calculations of solvent mixtures or use as electrolytes for various applications.
\end{abstract}

\section{INTRODUCTION}

Ionic liquids have attracted great attention in the past few years based on their prospective physicochemical features and electrochemical properties. ${ }^{1-8}$ However, the use of pure ionic liquids is often restricted based on the high viscosity of those liquids. Mixtures of ionic liquids and organic carbonates are therefore mentioned to be more suitable as alternative electrolyte solvents for use in various electrochemical approaches like lithium-ion batteries or supercaps based on their improve in safety and flammability. ${ }^{9-13}$ An examination of the literature shows that comparatively few systematic studies about physicochemical properties of binary mixtures containing ionic liquids and organic carbonates have been performed so far. ${ }^{14-22}$ However, systematic studies are highly necessary with reliable experimental proof for a better understanding of the chemical and physicochemical behavior of mixtures and for studying of the complex interplay between multiple ions and organic molecules in such mixtures. Such experimental data are the basis for the validation of theoretical calculations ${ }^{23}$ and an evaluation of possible applications. The compounds 1-ethyl-3methylimidazolium bis(trifluoromethanesulfonyl)azanide (EMIM-TFSA; also known as bis(trifluoromethanesulfonyl)imide $(\text { TFSI })^{24}$ ) and ethylene carbonate (EC) are chosen based on their prospective properties for electrochemical applications such as conductivity, solid electrolyte interface (SEI) forming agent and safety improvement.
In this study, binary mixtures of EMIM-TFSA and EC are presented in detail. After a short introduction of the pure solvents and a short summary about literature results, the mixture EMIM-TFSA/EC is described with respect to fundamental DSC, density, and rheological and conductivity data.

\section{EXPERIMENTAL SECTION}

Materials. Ethylene carbonate, EMIM-TFSA, and Li-TFSA (see Table 1) were dried by using a coulometric Karl Fischer titrator. The reagents were placed into a Thermoprep oven (831 KF Coulometer and $860 \mathrm{KF}$ Thermoprep oven from Metrohm, $120{ }^{\circ} \mathrm{C}$ ) and a continuous gas flow (dried air) was bubbled through the liquid. The water content of the gas flow was detected in the Coulometer below a water drift of $<1 \mu \mathrm{g}$ $\min ^{-1}$. After this drying procedure, the water content of was determined to be less than $20 \mathrm{ppm}$. The preparation of the mixtures was performed in an argon-filled glovebox (MBraun $\mathrm{GmbH}$ ) with oxygen and water levels below $0.5 \mathrm{ppm}$. All the measurements were taken at atmospheric pressure $(p)$ and are reported to $0.1 \mathrm{MPa}$ with standard uncertainty $(u) u(p)=5$ $\mathrm{kPa}$.

Received: April 13, 2015

Accepted: December 21, 2015

Published: December 29, 2015 
Table 1. Sample Description Table

\begin{tabular}{llcccc} 
chemical name & \multicolumn{1}{c}{ source } & initial fraction purity & purification method & final fraction purity & final water contamination \\
EC $^{a}$ & Sigma-Aldrich & $99 \%$ & $\mathrm{KF}^{d}$ & $\geq 99 \%$ & $\leq 20 \mathrm{ppm}$ \\
EMIM-TFSA $^{b}$ & Iolitec & $\geq 99 \%$ & $\mathrm{KF}^{d}$ & $\geq 99 \%$ & $\leq 20 \mathrm{ppm}^{d}$ \\
Li-TFSA $^{c}$ & Iolitec & $\geq 99 \%$ & $\mathrm{KF}^{d}$ & $\geq 99 \%$ & $\mathrm{KF}^{d}$
\end{tabular}

${ }^{a}$ Ethylene carbonate. ${ }^{b}$ 1-Ethyl-3-methylimidazolium bis(trifluoromethanesulfonyl)azanide. ${ }^{c}$ Lithium bis(trifluoromethanesulfonyl)azanide. ${ }^{d}$ Drying procedure and measurement according to Karl Fischer as described in the manuscript text.

Conductivity Measurements. The ionic conductivity of the mixtures was measured by the standard complex impedance method, using a Zahner Zennium IM6 electrochemical workstation in the frequency range from $1 \mathrm{kHz}$ to $1 \mathrm{MHz}$. A $1.6 \mathrm{~mL}$ closed cell ( $850 \mu \mathrm{L}$ solvent) from RHD instruments is used for the measurements. In the phase minimum of $0^{\circ}$, the impedance value $|\vec{Z}|$ was used as ohmic resistance for calculating the specific conductivity $\kappa$ according to $\kappa=C /|\vec{Z}|$ with the cell constant of $C \approx 17 \mathrm{~cm}^{-1}$. The exact cell constant $(u(C)=0.01$. $C)$ was received by measuring a standard solution $(1.413 \mathrm{mS}$ $\mathrm{cm}^{-1}$ at $25^{\circ} \mathrm{C}$, Hanna Instruments, HI 70031). The RHD test cell was filled inside the glovebox to exclude water contamination.

Viscosity Measurements. Dynamic viscosity was measured using a Malvern Gemini HR Nano rotational rheometer. These experiments were performed by using a solvent evaporation protecting cover in air. Binary mixtures of EMIM-TFSA and EC were measured with $60 / 2^{\circ}$ cone geometry for higher accuracy with a protection cap. Twentyfive values of the viscosity were measured equidistantly between a shear rate of $\dot{\gamma}=70 \mathrm{~s}^{-1}$ and $\dot{\gamma}=140 \mathrm{~s}^{-1}$ at each temperature. The average of the viscosity $\bar{\eta}$ of the Newtonian mixtures at each temperature is calculated according to $\bar{\eta}=\frac{1}{n} \sum_{n}^{i=1} m_{i}$ and the standard error which is given by $\sigma(\bar{\eta})=\frac{\sqrt{\operatorname{Var}(\eta)}}{\sqrt{n}}$, is $\leq 0.07$ $\mathrm{mPa} \cdot \mathrm{s}$ for all measurements. It was verified between $\dot{\gamma}=1-200$ $\mathrm{s}^{-1}$ that the viscosity is independent of the sheer rate (Newtonian fluid).

Density Measurements. The density of selected mixtures was obtained by a precision densitometer from Anton Paar (DMA4500M) in a temperature range of $20{ }^{\circ} \mathrm{C}$ to $80{ }^{\circ} \mathrm{C}$. The test preparation in the measurement device, the mixtures are exposed to air for $<5 \mathrm{~s}$. The standard uncertainty of the temperature during the measurement was $u(T)=0.01{ }^{\circ} \mathrm{C}$.

DSC Measurements. The mixtures were investigated by differential scanning calorimetry (DSC) regarding their phase behavior (Netzsch DSC 204 F1 Phoenix, Al crucible closed). The measurements were carried out from -150 to $100{ }^{\circ} \mathrm{C}$ at a heating rate of 10 and $20 \mathrm{~K} \mathrm{~min}^{-1}$ in argon atmosphere. Standard uncertainty $u$ of the temperature is $u(T)=3 \mathrm{~K}$.

\section{RESULTS AND DISCUSSION}

In this study, the binary mixture EMIM-TFSA/EC is investigated in detail. The chemical structures of the compounds are displayed in Figure 1. All ratios are listed as wt/wt ratios, and an overview about both liquids compared to literature results is provided in Table 2. It is observed that all mixtures remain in the liquid state at room temperature except for mixture 10:90 wt/wt EMIM-TFSA/EC (completely soluble at approximately $40{ }^{\circ} \mathrm{C}$ ).

The binary mixture EMIM-TFSA/EC is investigated regarding density, viscosity, phase transitions, and conductivity. Both solvents had been dried carefully before preparing the

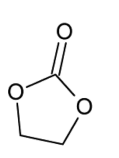

EC

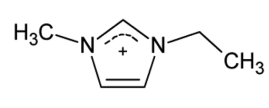

$\mathrm{EMIM}^{+}$<smiles>O=S(=O)(N[SH-]S(=O)(=O)C(F)(F)F)C(F)(F)F</smiles>

TFSA $^{-}$
Figure 1. Chemical structures of ethylene carbonate (EC), 1-ethyl-3methylimidazolium $\left(\mathrm{EMIM}^{+}\right)$, and bis(trifluoromethanesulfonyl)azanide $\left(\mathrm{TFSA}^{-}\right)$.

mixtures to exclude water traces which influence the measurements distinctly. At $20^{\circ} \mathrm{C}$, density and viscosity values of the mixtures are continuously decreasing with increasing EC content. In contrast, the conductivity data run through a maximum value at 60:40 (EMIM-TFSA/EC).

Temperature dependent density values of the mixtures are depicted in Figure 2 and listed in Table 3. The density $d$ of a binary ideal mixture which is composed of solvent 1 (mass $m_{1}$, density $d_{1}$, volume $V_{1}$ ) and solvent 2 (mass $m_{2}$, density $d_{2}$, volume $V_{2}$ ) can be calculated according to eq 1 . Here, the excess volume $V^{\Xi}=V-\left(V_{1}+V_{2}\right)$ which results from interactions between the molecules of the two solvents, is neglected.

$$
d=\frac{m_{1}+m_{2}}{\frac{m_{1}}{d_{1}}+\frac{m_{2}}{d_{2}}}=\frac{m_{1}+m_{2}}{V_{1}+V_{2}}
$$

The theoretically calculated values for ideal mixtures are depicted in Figure 2a for comparison (labeled as "fit"). It can be seen that the assumption of an ideal mixture is a good approximation for calculating the density of the EMIM-TFSA/ EC mixtures. In Figure $2 b$, the molar excess volume is plotted against the molar fraction of EMIM-TFSA for a more detailed analysis. The maximum relative deviations between the density of the measurement data and the results of eq 1 are $1.7 \%$ ( 40 $\left.{ }^{\circ} \mathrm{C}\right), 1.9 \%\left(60{ }^{\circ} \mathrm{C}\right)$ and $2.0 \%\left(80{ }^{\circ} \mathrm{C}\right)$. The temperature dependency of the excess molar volume of EMIM-TFSA/EC mixtures is rather small (Figure $2 b$ ). When small amounts of EC (from right to left in Figure 2b) are added to EMIM-TFSA, a slight decrease of the molar excess volume is observed which can be explained by attractive interactions between EMIMTFSA molecular aggregates and EC molecules. These attractive interactions can be caused by dipol-dipol interactions from oxygen (EC) to the imidazolium ring as well as hydrogen bonds between $\mathrm{EMIM}^{+}$and EC. In this case, the mixture becomes denser based on small EC molecules which are placed between larger EMIM-TFSA aggregates. By further increasing the amount of EC, a slightly positive molar excess volume is observed. It is supposed that the ionic EMIM-TFSA aggregates are segregated increasingly and the ions are coordinated less strongly in the mixture. In this case, a weakening of strong electrostatic interactions between $\mathrm{EMIM}^{+}$and $\mathrm{TFSA}^{-}$by EC can take place. However, all these effects are balanced in this solvent mixture because only small excess values are measured. 
Table 2. Overview about Experimental and Literature Values of Density $(d)$, Viscosity $(\eta)$, Conductivity ( $\boldsymbol{\kappa})$, and DSC Results $\left(T_{\mathrm{m}}=\right.$ Melting Point; $T_{\mathrm{g}}=$ Glass Transition Temperature $)$ of Pure Mixtures at the Specified Temperature at Atmospheric Pressure $(p=0.1 \mathrm{MPa})$

\begin{tabular}{|c|c|c|c|c|c|c|c|c|c|c|}
\hline$T$ & $d$ & $d$ & $\kappa$ & $\kappa$ & $\eta$ & $\eta$ & $T_{\mathrm{m}}$ & $T_{\mathrm{m}}$ & $T_{\mathrm{g}}$ & $T_{\mathrm{g}}$ \\
\hline \multirow[t]{2}{*}{${ }^{\circ} \mathrm{C}$} & $\mathrm{g} \mathrm{cm}^{-3}$ & $\mathrm{~g} \mathrm{~cm}^{-3}$ & $\mathrm{mS} \mathrm{cm}^{-1}$ & $\mathrm{mS} \mathrm{cm}^{-1}$ & $\mathrm{mPa} \mathrm{s}$ & $\mathrm{mPa} \mathrm{s}$ & ${ }^{\circ} \mathrm{C}$ & ${ }^{\circ} \mathrm{C}$ & K & $\mathrm{K}$ \\
\hline & this work & ref & this work & ref & this work & ref & this work & ref & this work & ref \\
\hline \multicolumn{2}{|c|}{ EMIM-TFSA } & & & & & & $\begin{array}{l}-6.7^{a, c} \\
-10.5^{b, c}\end{array}$ & $\begin{array}{l}-12^{25} \\
-14.7^{26}\end{array}$ & $-89.4^{c}$ & $-92^{27 d}$ \\
\hline 20 & 1.5240 & $\begin{array}{l}1.52208^{28} \\
1.52^{26}\end{array}$ & 7.6 & $7.73^{29}$ & 41.6 & $39.07^{30}$ & & & & \\
\hline 25 & 1.5168 & $\begin{array}{l}1.51696^{28} \\
1.51^{25} \\
1.5193^{30} \\
1.5180^{31}\end{array}$ & 9.0 & $\begin{array}{l}9.12^{29} \\
9.2^{25} \\
9.21^{30}\end{array}$ & 33.9 & $\begin{array}{l}34^{25} \\
32.46^{30} \\
31.47^{31}\end{array}$ & & & & \\
\hline 40 & 1.5038 & $1.5043^{30}$ & 13.6 & $14.14^{30}$ & 19.1 & $19.97^{30}$ & & & & \\
\hline \multicolumn{3}{|c|}{ ethylene carbonate } & & & & & $\begin{array}{l}41.3^{a, c} \\
36.0^{b, c}\end{array}$ & $35-38^{e}$ & & \\
\hline 40 & 1.3219 & $1.32^{32}$ & $<0.01$ & & 1.81 & $1.93^{32}$ & & & & \\
\hline
\end{tabular}

${ }^{a}$ At peak maximum. ${ }^{b}$ Onset temperature. ${ }^{c}$ At scan rate of $5 \mathrm{~K} / \mathrm{min} .{ }^{d}$ At scan rate of $10 \mathrm{~K} / \mathrm{min} .{ }^{e}$ Value taken from the datasheet (Sigma-Aldrich). Standard uncertainties $u$ for values from this work are $u(d)=0.0005 \mathrm{~g} \mathrm{~cm}^{-3} ; u(\eta)=0.05 \cdot \eta ; u(\kappa)=0.03 \cdot \kappa, u(p)=5 \mathrm{kPa} ; u(T \kappa)=0.1 \mathrm{~K} ; u\left(T_{\eta}\right)=0.1$ $\mathrm{K} ; u\left(T_{d}\right)=0.01 \mathrm{~K} ; u\left(T_{\mathrm{m}}\right)=3 \mathrm{~K} ; u\left(T_{\mathrm{g}}\right)=3 \mathrm{~K}$ (specified temperature during conductivity $(T \kappa)$, density $\left(T_{d}\right)$ and viscosity $\left(T_{\eta}\right)$ measurement).
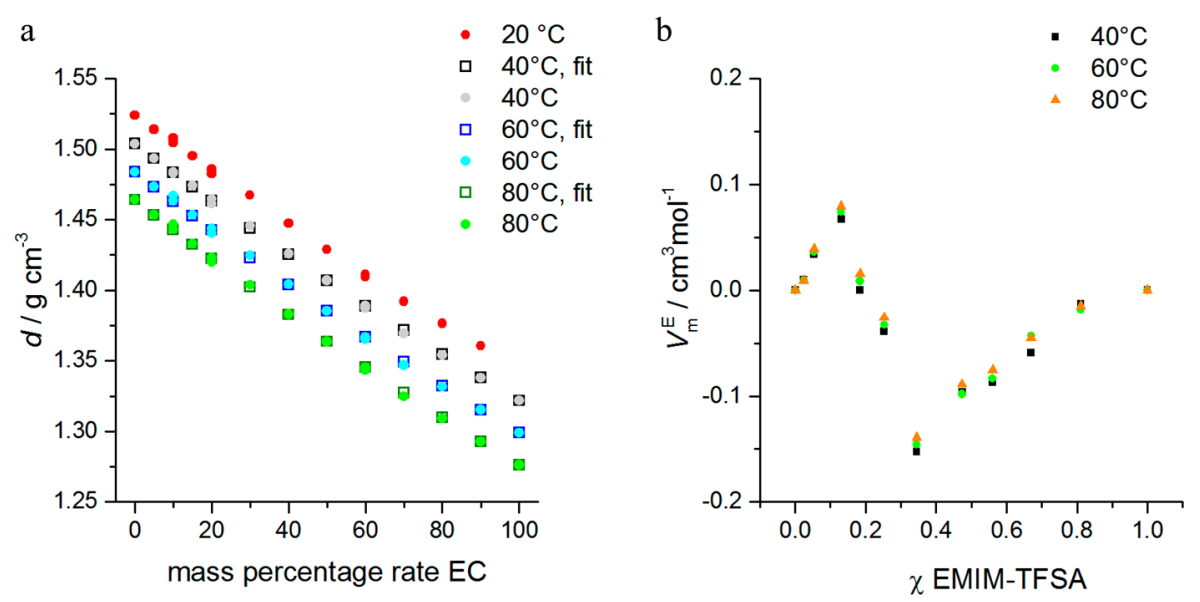

Figure 2. (a) Density of the EMIM-TFSA/EC mixtures at $20-80{ }^{\circ} \mathrm{C}$. The theoretical calculations according to eq 1 are labeled as "fit". Here, the density values of the pure compounds are used. (b) Molar excess volume of the EMIM-TFSA/EC binary mixtures as a function of the EMIM-TFSA mole fraction at different temperatures.

Vraneš et al. mentioned that the maximum molar excess volume $V_{m}^{\rightleftarrows}$ at $40{ }^{\circ} \mathrm{C}$ for a binary mixture composed of 1-butyl3-methylimidazolium bis(trifluoromethanesulfonyl)azanide and propylene carbonate is $V_{m}^{\mathrm{E}}=-0.44 \mathrm{~cm}^{3} \mathrm{~mol}^{-1}$ at $\chi_{\mathrm{IL}}=0.58$ (BMIM-TFSA:PC $=85.2: 14.8 \mathrm{wt} / \mathrm{wt}) .{ }^{14}$ The larger value of the excess volume compared to EMIM-TFSA/EC mixture is supposed to result from larger molecules of BMIM-TFSA (vs EMIM-TFSA) and propylene carbonate (vs EC). Mixtures of EMIM-Et ${ }_{2} \mathrm{SO}_{4} / \mathrm{PC}$ are studied by Lehmann et al., where a maximum excess volume is received at similar molar ratios of $\chi_{\mathrm{IL}}=0.696$ to be $V_{m}^{\mathrm{E}}=-0.33 \mathrm{~cm}^{3} \mathrm{~mol}^{-1}$ (at $25^{\circ} \mathrm{C}$ ). ${ }^{33}$ GeppertRybczyńska et al. investigated several solvents in binary mixtures with EMIM-TFSA. ${ }^{28}$ Compared to literature values of $V_{m}^{\mathrm{E}}$ for EMIM-TFSA/organic solvent binary mixtures, ${ }^{14,28}$ the deviation from the ideal behavior is relatively small in the case of EC. The maximum values $V_{m}^{\mathrm{E}}$ for selected binary mixtures of EMIM-TFSA/organic solvents can be arranged (from positive to negative) in the order of DMSO > EC > acetonitrile $>$ tetrahydrofuran ${ }^{28}$ where the maximum value of $V_{m}^{\mathrm{E}}$ is obtained at $\chi$ (EMIM-TFSA) $\approx 0.3-0.4$ for all solvents.
In Figure 3, the results of DSC measurements between $(-120$ to +100$){ }^{\circ} \mathrm{C}$ during cooling (Figure 3a) and heating (Figure $3 \mathrm{~b}$ ) are shown at a rate of $10 \mathrm{~K} \cdot \mathrm{min}^{-1}$. The values are listed in Table 4. It is observed that pure EMIM-TFSA (see Figure SI-1 for detailed DSC measurement of pure EMIMTFSA) exhibits two crystalline phases. On the basis of the results reported by Paulechka et al., the sequence of these phases can be assigned to crIV-crII-liq (from 123 to $373 \mathrm{~K}$ ). ${ }^{34}$ The phase transitions are extracted from DSC measurement at $5 \mathrm{~K} \mathrm{~min}^{-1}$ (crIV-crII at $-16.2{ }^{\circ} \mathrm{C}$ and crII-liq at $-6.8{ }^{\circ} \mathrm{C}$; $u(T)=2.5^{\circ} \mathrm{C}$ ). These temperatures are in accordance with the results without annealing before the measurement described by Paulechka et al. ${ }^{34}$ It should be noted that these temperatures based on DSC measurements depend on scan rates and are determined at peak maximum.

The glass transition $T_{g}$, which is a qualitative measure of the ion mobility and the ion-ion interactions, decreases continuously when the EC amount is increased (heating at $5 \mathrm{~K}$. $\min ^{-1}$, Figure 4, Table 4). This can be ascribed to the plasticizing effect of EC which is in accordance with the density 
Table 3. Density Data $(d)$ of the Solvent Mixtures at

Pressure $\boldsymbol{p}=\mathbf{0 . 1} \mathrm{MPa}$ (Standard Uncertainties $\boldsymbol{u}$ Are $\boldsymbol{u}(\chi)=$ $\left.0.0002, u(d)=0.0005 \mathrm{~g} \mathrm{~cm}^{-3}, u(p)=5 \mathrm{kPa}, u(T)=0.01 \mathrm{~K}\right)$

\begin{tabular}{|c|c|c|c|c|c|}
\hline EMIM-TFSA/EC & $\chi$ & $d$ & $d$ & $d$ & $d$ \\
\hline wt/wt & $\mathrm{EC}$ & $\begin{array}{l}\mathrm{g} \mathrm{cm}^{-3} \\
\left(20^{\circ} \mathrm{C}\right)\end{array}$ & $\begin{array}{l}\mathrm{g} \mathrm{cm}^{-3} \\
\left(40^{\circ} \mathrm{C}\right)\end{array}$ & $\underset{\left(60^{\circ} \mathrm{C}\right)}{\mathrm{g} \mathrm{cm}^{-3}}$ & $\begin{array}{l}\mathrm{g} \mathrm{cm}^{-3} \\
\left(80^{\circ} \mathrm{C}\right)\end{array}$ \\
\hline $0: 100$ & 1.0000 & & 1.3219 & 1.2991 & 1.2763 \\
\hline 5:95 & 0.9883 & $1.3607^{a}$ & 1.3379 & 1.3153 & 1.2927 \\
\hline $10: 90$ & 0.9756 & $1.3765^{a}$ & 1.3541 & 1.3316 & 1.3092 \\
\hline $15: 85$ & 0.9618 & $1.3920^{a}$ & 1.3693 & 1.3469 & 1.3247 \\
\hline 20:80 & 0.9467 & $1.4096^{a}$ & 1.3873 & 1.3653 & 1.3434 \\
\hline $30: 70$ & 0.9120 & 1.4290 & 1.4070 & 1.3852 & 1.3636 \\
\hline $40: 60$ & 0.8696 & 1.4476 & 1.4259 & 1.4044 & 1.3831 \\
\hline $50: 50$ & 0.8163 & 1.4673 & 1.4459 & 1.4247 & 1.4037 \\
\hline 60:40 & 0.7476 & 1.4858 & 1.4614 & 1.4405 & 1.4199 \\
\hline $70: 30$ & 0.6557 & 1.4951 & 1.4742 & 1.4535 & 1.4332 \\
\hline $80: 20$ & 0.5263 & 1.5046 & 1.4828 & 1.4669 & 1.4468 \\
\hline 90:10 & 0.3305 & 1.5141 & 1.4936 & 1.4735 & 1.4536 \\
\hline 100:0 & 0.0000 & 1.5240 & 1.5038 & 1.4838 & 1.4642 \\
\hline
\end{tabular}

${ }^{a}$ Data are received from supercooled liquid.

results (excess molecular volume). By adding EC to EMIMTFSA, attractive electrostatic interactions between $\mathrm{EMIM}^{+}$and TFSA $^{-}$ions decrease caused by a segregation of EMIM-TFSA aggregates, and a higher degree of molecular disorder arises. Similar trends had also been observed in binary mixtures of ammonium-based ionic liquids and EC or dimethyl carbonate (DMC). ${ }^{16}$ In the binary EMIM-TFSA/EC mixture, a glass transition could be detected up to a mixture of 60/40 (EMIMTFSA/EC wt/wt), whereas at higher EC concentrations no
Table 4. DSC Data of EMIM-TFSA/EC Mixtures (Melting Temperature $\left(T_{\mathrm{m}}\right)$, Crystallizing Temperature $\left(T_{\mathrm{K}}\right)$, Glass Transition Temperature $\left(T_{\mathrm{g}}\right)$ ) Measured in Closed Al Crucibles (Standard Uncertainties $u$ Are $u(\chi)=0.0002 ; u(T)$ $\left.=3{ }^{\circ} \mathrm{C}\right)^{a}$

\begin{tabular}{|c|c|c|c|c|c|}
\hline EMIM-TFSA/EC & $\chi$ & $\begin{array}{c}\text { solid- } \\
\text { liquid } \\
\text { transition }\end{array}$ & $T_{\mathrm{K}}$ & $T_{\mathrm{m}}$ & $T_{\mathrm{g}}$ \\
\hline $\mathrm{wt} / \mathrm{wt}$ & $\mathrm{EC}$ & $\begin{array}{c}{ }^{\circ} \mathrm{C} \\
(\mathrm{DSC}) \\
(\text { peak } \\
\max )^{b}\end{array}$ & $\begin{array}{c}{ }^{\circ} \mathrm{C} \\
(\mathrm{DSC}) \\
(\text { peak } \\
\max )^{b}\end{array}$ & $\begin{array}{c}{ }^{\circ} \mathrm{C} \\
(\mathrm{DSC}) \\
(\text { peak } \\
\max )^{b}\end{array}$ & $\begin{array}{c}{ }^{\circ} \mathrm{C} \\
\text { (DSC) } \\
\text { (point of } \\
\text { inflection) }{ }^{c}\end{array}$ \\
\hline 100:0 & 0.0000 & & & -6.7 & -89.4 \\
\hline $90: 10$ & 0.3305 & & & -25.5 & -91.3 \\
\hline $80: 20$ & 0.5263 & -27.9 & & -14.0 & -92.3 \\
\hline $70: 30$ & 0.6557 & -27.1 & & -0.9 & -95.3 \\
\hline $60: 40$ & 0.7476 & -30.8 & & 8.8 & -97.0 \\
\hline $50: 50$ & 0.8163 & -28.1 & -28.9 & 16.6 & \\
\hline $40: 60$ & 0.8696 & -28.9 & -8.3 & 24.2 & \\
\hline $30: 70$ & 0.9120 & -28.8 & -5.3 & 28.3 & \\
\hline $20: 80$ & 0.9467 & -28.1 & 5.9 & 34.2 & \\
\hline 10:90 & 0.9756 & -30.1 & 4.4 & 36.5 & \\
\hline $0: 100$ & 1.0000 & & 3.8 & 41.3 & \\
\hline
\end{tabular}

${ }^{a_{T}}$ The experimental pressure during the measurement inside the closed Al crucibles was not determined but estimated to be $p=0.1 \mathrm{MPa}$ $(u(p)=10 \mathrm{kPa})$ at $T \ll T_{\mathrm{b}}\left(T_{\mathrm{b}}=\right.$ boiling point $)$. Additional data points (DSC results) are listed in the supporting information (Table SI-1). ${ }^{b}$ DSC: heating/cooling at $10 \mathrm{~K} \mathrm{~min}^{-1}$; the peak maximum was chosen because of the heavily detectable onset of the $T_{\mathrm{m}} . T_{\mathrm{K}}$ is extracted from Figure 3a (cooling cycle). ${ }^{c}$ The glass transition temperature is extracted from heating-up curves at $5 \mathrm{~K} \cdot \mathrm{min}^{-1}$.
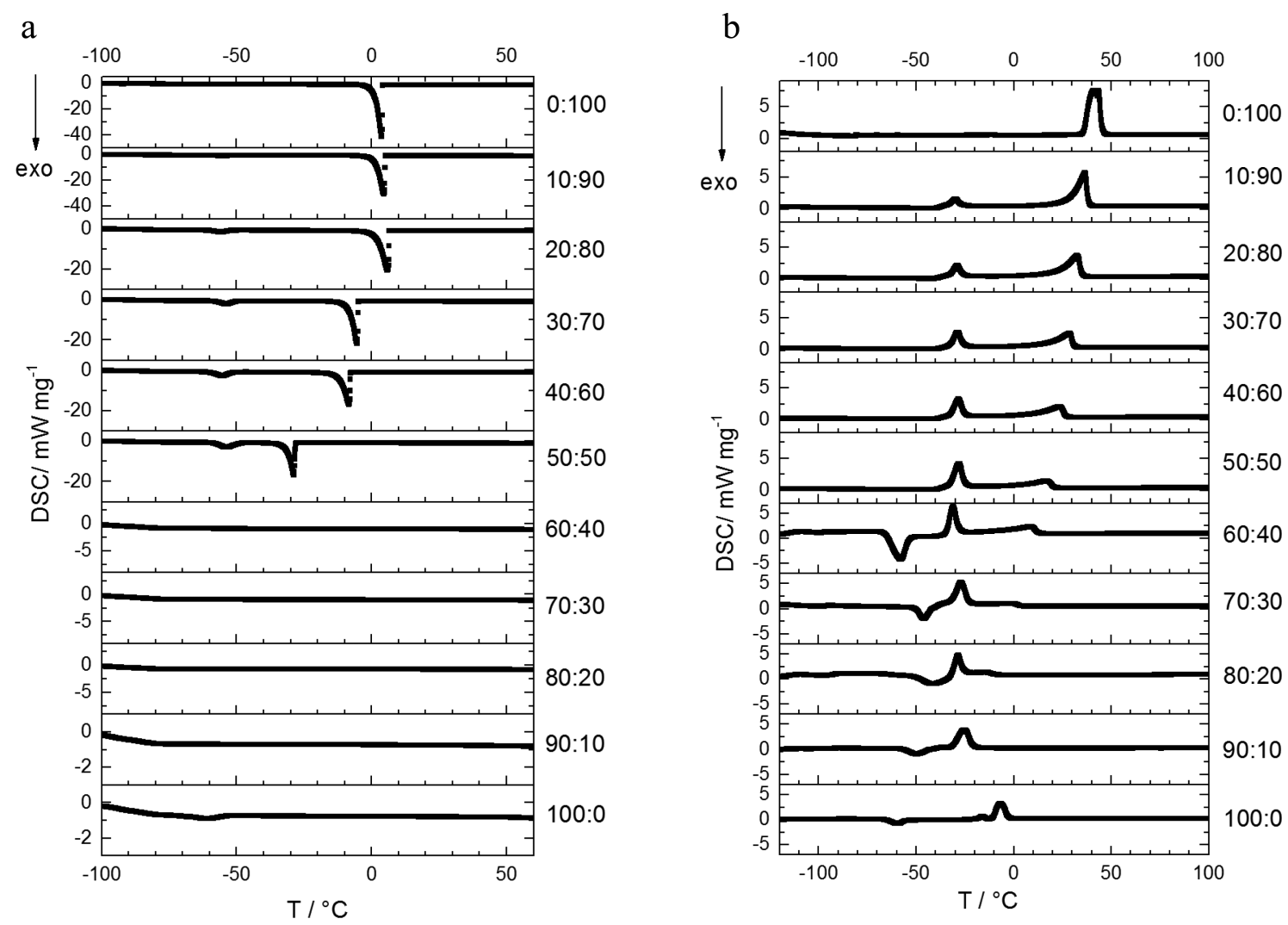

Figure 3. DSC measurements of the EMIM-TFSA: EC (wt/wt) mixtures. Behavior of the mixtures during cooling $\left(\mathrm{a}, 10 \mathrm{~K} \mathrm{~min}{ }^{-1}\right)$ and heating $(\mathrm{b}$, $\left.10 \mathrm{~K} \mathrm{~min}^{-1}\right)$ in the temperature range of $(-120$ to +100$){ }^{\circ} \mathrm{C}$ (exo down). 


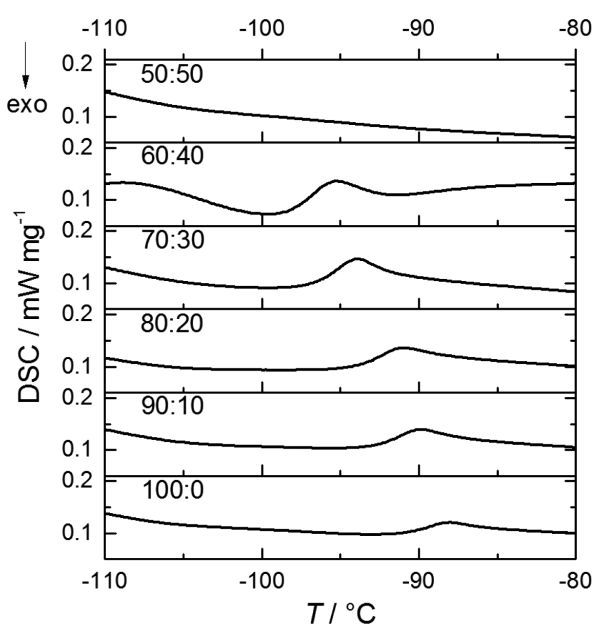

Figure 4. DSC measurements around the glass transition of EMIMTFSA: EC (wt/wt) mixtures during heating at $5 \mathrm{~K} \mathrm{~min}^{-1}$. No glass transition is observed at higher EC concentrated mixtures (exo down).

glass transition temperature could be observed (heating at (520) $\left.\mathrm{K} \cdot \mathrm{min}^{-1}\right)$. It can be seen that during cooling a crystallization peak $\left(T_{\mathrm{K}}\right)$ exists up to $50 \mathrm{wt} \%$ EMIM-TFSA, whereas at higher EMIM-TFSA concentrations no crystallization peak is observed (also at $20 \mathrm{~K} \mathrm{~min}^{-1}$ ). For those mixtures, a recrystallization peak occurs during heating. Thus, mixtures of EMIM-TFSA > 50 wt \% exhibit a supercooled melting during cooling at relative fast cooling rates of (10 to 20) $\mathrm{K} \mathrm{min}^{-1}$. Additionally it is found that a solid-solid transition arises within a concentration range of 20:80 to 50:50 (EMIM-TFSA:EC) at $-50{ }^{\circ} \mathrm{C}$ to $-60{ }^{\circ} \mathrm{C}$ (only visible during cooling, Figure 3a).

The melting temperature $T_{\mathrm{m}}$ at peak maximum increases continuously from $-25{ }^{\circ} \mathrm{C}$ (EMIM-TFSA:EC $\left.=90: 10\right)$ to +41 ${ }^{\circ} \mathrm{C}$ (EMIM-TFSA:EC $\left.=0: 100\right)$ which correlates very well with the melting point of EC ( 35 to $38{ }^{\circ} \mathrm{C}$ ). The onset of the melting temperature of pure $\mathrm{EC}$ is detected at $36{ }^{\circ} \mathrm{C}(5 \mathrm{~K}$ $\left.\mathrm{min}^{-1}\right)$. For a more detailed analysis, additional mixture ratios are analyzed and a phase diagram is extracted (Figure 5). It can be observed that the high melting point of EC can significantly be reduced by adding EMIM-TFSA. In the process, a melting point depression of $\mathrm{EC}$ on the order of some $10{ }^{\circ} \mathrm{C}$ can be received easily $\left(\chi_{\text {EMIM-TFSA }}=0.2\right.$ corresponds to $\sim 50: 50 \mathrm{wt} \%$ ).

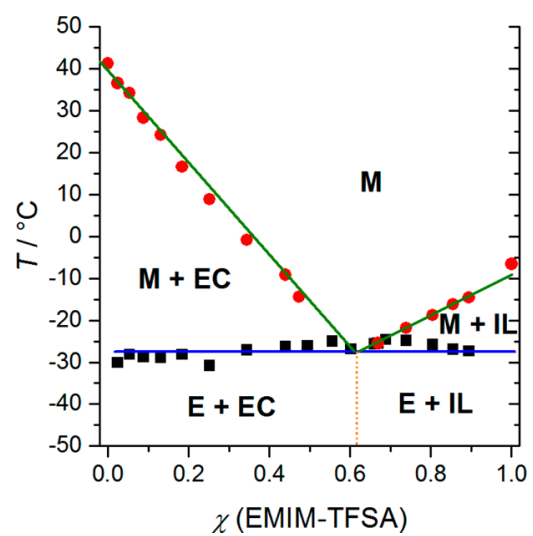

Figure 5. Phase diagram of $(\chi)$ EMIM-TFSA $+(1-\chi)$ EC $(\chi$ is mole fraction; IL = EMIM-TFSA; $\mathrm{E}=$ eutectic mixture; $\mathrm{M}=$ melting/liquid mixture).
It should be noted that all mixtures exhibit an endothermic peak (Figure 5) at $-27.0{ }^{\circ} \mathrm{C}$ which is independent of the mixture composition and which is not present in the pure compounds. This peak can be assigned to an eutectic composition at $\chi=0.62$ (mole fraction of EMIM-TFSA) which is also described for pyrrolidinium-based ionic liquid (IL) $/$ EC mixtures at $\chi$ (IL) $=0.55 .^{20}$ However, the eutectic temperature is lower in the EMIM-TFSA/EC system than in the EC/N-methyl- $N$-pentylpyrrolidinium TFSA solvent mixture $\left(\sim-17{ }^{\circ} \mathrm{C}\right) .{ }^{20}$ Such a eutectic behavior cannot be observed when lithium salts (e.g., lithium bis(trifluoromethanesulfonyl)azanide (LiTFSA or LiTFSI) are added to the solvent mixture (details are not shown here). Remarkably, the solid-liquid curves in the phase diagram (Figure 5) exhibit a straight behavior instead of a convex shape as usually observed. Thus, the temperature-dependency of the solubility of EC in EMIM-TFSA as well as EMIM-TFSA in EC conforms to an almost linear behavior.

Temperature-dependent viscosity data of pure compounds and mixtures thereof are depicted in Figure 6 and listed in

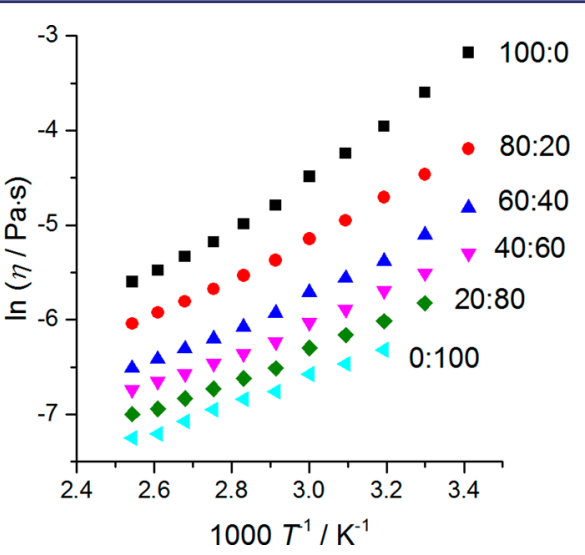

Figure 6. Temperature-dependent Arrhenius plots of the viscosity data in the temperature range of $(20 \text { to } 120)^{\circ} \mathrm{C}$.

Table 5 between 20 and $120{ }^{\circ} \mathrm{C}$. All viscosity values decrease with an increase in the temperature. It can be observed, that the

Table 5. Viscosity Data $(\eta)$ of Selected Solvent Mixtures (wt/wt ratio EMIM-TFSA:EC) in mPa.s at Pressure $p=0.1$ MPa (Standard Uncertainties, $u$, are $u(\eta)=0.05 \cdot \eta, u(p)=5$ $\mathrm{kPa}, u(\chi)=0.0002, u(T)=0.1 \mathrm{~K})$

\begin{tabular}{|c|c|c|c|c|c|c|}
\hline & $100: 0^{a}$ & $80: 20^{a}$ & $60: 40^{a}$ & $40: 60^{a}$ & $20: 80^{a}$ & $0: 100^{a}$ \\
\hline$T$ & $\begin{array}{c}\chi^{b}= \\
0.0000\end{array}$ & $\begin{array}{c}\chi^{b}= \\
0.5263\end{array}$ & $\begin{array}{c}\chi^{b}= \\
0.7476\end{array}$ & $\begin{array}{c}\chi^{b}= \\
0.8163\end{array}$ & $\begin{array}{c}\chi^{b}= \\
0.9467\end{array}$ & $\begin{array}{c}\chi^{b}= \\
1.0000\end{array}$ \\
\hline $20{ }^{\circ} \mathrm{C}$ & 41.6 & 15.1 & 8.1 & 5.0 & & \\
\hline $30{ }^{\circ} \mathrm{C}$ & 27.3 & 11.5 & 6.1 & 4.1 & 3.0 & \\
\hline $40{ }^{\circ} \mathrm{C}$ & 19.1 & 9.0 & 4.6 & 3.4 & 2.4 & 1.81 \\
\hline $50{ }^{\circ} \mathrm{C}$ & 14.4 & 7.1 & 3.9 & 2.8 & 2.1 & 1.56 \\
\hline $60{ }^{\circ} \mathrm{C}$ & 11.3 & 5.8 & 3.3 & 2.4 & 1.84 & 1.40 \\
\hline $70{ }^{\circ} \mathrm{C}$ & 8.3 & 4.6 & 2.7 & 1.97 & 1.48 & 1.16 \\
\hline $80{ }^{\circ} \mathrm{C}$ & 6.8 & 4.0 & 2.3 & 1.74 & 1.33 & 1.07 \\
\hline $90^{\circ} \mathrm{C}$ & 5.6 & 3.4 & 2.03 & 1.56 & 1.20 & 0.96 \\
\hline $100{ }^{\circ} \mathrm{C}$ & 4.8 & 3.0 & 1.83 & 1.40 & 1.08 & 0.85 \\
\hline $110^{\circ} \mathrm{C}$ & 4.2 & 2.7 & 1.63 & 1.29 & 0.97 & 0.74 \\
\hline $120^{\circ} \mathrm{C}$ & 3.7 & 2.4 & 1.49 & 1.19 & 0.91 & 0.71 \\
\hline
\end{tabular}

${ }^{a}{ }_{\mathrm{wt}} / \mathrm{wt}$ of EMIM-TFSA/EC. ${ }^{b} \chi$ (ethylene carbonate) in mixture EMIM-TFSA/EC. 
addition of EC significantly reduces the viscosity values of the ionic liquid EMIM-TFSA which can be attributed to the disturbance of the ionic liquid aggregates by the EC molecules (as seen accordingly from DSC and density measurements). The viscosity of a $2.2 \mathrm{M}$ solution of EMIM-TFSA in EC is described by McEwen et al. ${ }^{22}$ Although the concentration can only be estimated (no density values were provided), the concentration can be assumed to be $\sim 60: 40$ wt \% (EMIMTFSA/EC). They proposed a viscosity value of $5.8 \mathrm{mPas}(26$ ${ }^{\circ} \mathrm{C}$ ) which is in good accordance with the values listed in Table 4.

The viscosity data are fitted according to the VogelFulcher-Tammann-Hesse (VFTH) eq 2 for describing and characterizing the molecular motion. ${ }^{35-37} \eta_{0}$ is the limiting viscosity, $B$ is a fitting parameter, $D$ is the Angell strength parameter $\left(D=B / T_{0}\right), \quad T_{0}$ is the ideal glass transition temperature, and $T$ is the absolute temperature. Additionally, the temperature dependence of the viscosity $\eta(T)$ can be discussed based on the fragility concept. ${ }^{38-40}$ The fitting data for temperature-dependent viscosity values are listed in Table 6 .

$$
\eta=\eta_{0} \exp \left(\frac{B}{T-T_{0}}\right)=\eta_{0} \exp \left(\frac{D \cdot T_{0}}{T-T_{0}}\right)
$$

Table 6. Free VFTH Fitting of the Viscosity Data ${ }^{a}$

\begin{tabular}{|c|c|c|c|c|c|c|c|}
\hline $\begin{array}{c}\text { ratio EMIM- } \\
\text { TFSA/EC }\end{array}$ & $\begin{array}{c}\eta_{0} \\
10^{-2}\end{array}$ & $T_{0}$ & & & $T_{\mathrm{g}}$ & & \\
\hline wt/wt & $\mathrm{mPas}$ & $\mathrm{K}$ & $D$ & $m$ & $\underset{\mathrm{DSC}^{b}}{\mathrm{~K}}$ & $R^{2}$ & $\begin{array}{l}\eta_{20}{ }^{\circ} \mathrm{C} / \\
\eta_{120^{\circ} \mathrm{C}}\end{array}$ \\
\hline 100:0 & 18.2 & 172.2 & 3.8 & 171 & 183.8 & 0.9997 & 11.3 \\
\hline $80: 20$ & 11.7 & 158.2 & 4.2 & 157 & 180.9 & 0.9994 & 7.8 \\
\hline $60: 40$ & 6.6 & 132.9 & 5.8 & 118 & 176.2 & 0.9999 & 6.1 \\
\hline $40: 60$ & 6.0 & 129.3 & 5.6 & 121 & $c$ & 0.9999 & 5.0 \\
\hline $20: 80$ & 6.3 & 130.8 & 5.0 & 134 & $c$ & 0.9998 & 6.0 \\
\hline $0: 100$ & 3.1 & 109.9 & 7.1 & 99 & $c$ & 0.9999 & 4.0 \\
\hline
\end{tabular}

${ }^{a}$ For the fitting procedure, the following initial fitting parameters are used: $\eta_{0}=0.2 \mathrm{mPa} \cdot \mathrm{s} ; D=4 ; T_{0}=160 \mathrm{~K}$. No additional assumptions were done during the fitting procedure otherwise mentioned (standard uncertainties $u$ are $u\left(T_{\mathrm{g}}\right)=3{ }^{\circ} \mathrm{C}, u(D)=0.025 \cdot D, u(m)=0.03 \cdot m$, $\left.u\left(T_{0}\right)=0.015 \cdot T_{0}, u\left(\eta_{0}\right)=0.05 \cdot \eta_{0}\right) .{ }^{b} \mathrm{DSC}$ : heating at $10 \mathrm{~K} / \mathrm{min}$; data taken from measurement. ${ }^{c}$ No $T_{\mathrm{g}}$ could be extracted from the measurement.

A free fit without applying additional data points at the glass transition temperature was performed within good correlations of $R^{2} \geq 0.9994$. In the fitting procedure, an Angell strength parameter $D$ of $3.8<D<7.1$ (fragile for $D<30)^{40}$ and a fragility factor $m$ of $99<m<171$ are received. Pure EMIMTFSA is already investigated by Schreiner at al. in which comparable values of $\eta_{0}$ (here, $18.2 \times 10^{-2} \mathrm{mPas}$ vs $22.72 \times$ $10^{-2} \mathrm{mPas}$ ), $B$ (here, $654 \mathrm{~K}$ vs $684 \mathrm{~K}$ ) and $T_{0}$ (here, $172 \mathrm{~K}$ vs $160 \mathrm{~K}$ ) are obtained (for standard uncertainties see Table 6). ${ }^{30}$ The pure ionic liquid 1-butyl-3-methylimidazolium TFSA (BMIM-TFSA) was studied by Harris et al. ${ }^{41}$ In this case, the following values were obtained: $\eta_{0}=16.3 \times 10^{-2} \mathrm{mPas} ; B=$ $766.3 \mathrm{~K} ; T_{0}=164.7 \mathrm{~K} ; D=4.7 . .^{41}$ Thus, an increase in fitting value $B$ can be observed when the alkyl chain length of the ionic liquid is larger which is equal to an increase in value $D$. Therefore, the behavior of the ionic liquid becomes a little stronger. Taken all together, the binary EMIM-TFSA/EC solvent mixtures can be classified as fragile $(D<30)^{38,39}$ in accordance with ionic liquid-based mixtures studied in literature. ${ }^{13,30,42}$

The ionic conductivities of the binary mixtures are shown in Figure 7, and all data are listed in Table 7. By adding EC to the

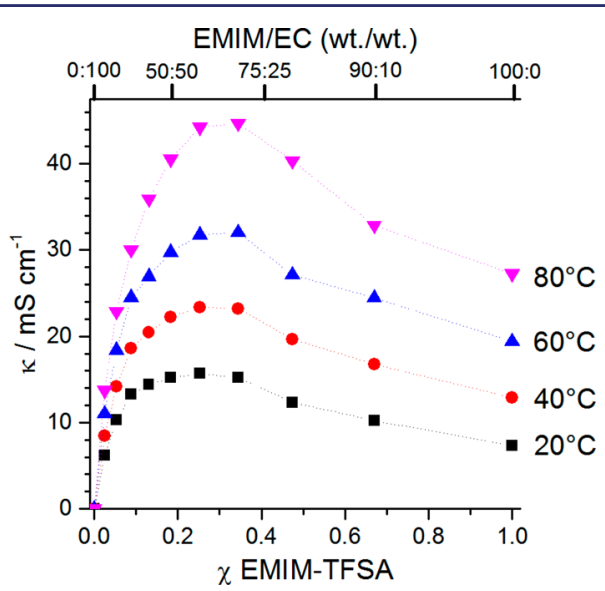

Figure 7. Temperature-dependent conductivity data of the mixtures. The $x$-axes mention the EMIM-TFSA/EC ratio (top) and the mole fraction (bottom).

Table 7. Conductivity Data $(\kappa)$ of the Solvent Mixtures at Pressure $p=0.1 \mathrm{MPa}$ (Standard Uncertainties $\boldsymbol{u}$ Are $\boldsymbol{u}(\boldsymbol{\kappa})=$ $0.03 \cdot \kappa, u(p)=5 \mathrm{kPa}, u(\chi)=0.0002, u(T)=0.1 \mathrm{~K})$

\begin{tabular}{|c|c|c|c|c|c|}
\hline EMIM-TFSA/EC & $\chi$ & $\kappa$ & $\kappa$ & $\kappa$ & $\kappa$ \\
\hline wt/wt & $\mathrm{EC}$ & 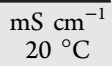 & $\begin{array}{c}\mathrm{mS} \mathrm{cm} \mathrm{cm}^{-1} \\
40^{\circ} \mathrm{C}\end{array}$ & $\begin{array}{c}\mathrm{mS} \mathrm{cm}{ }^{-1} \\
60{ }^{\circ} \mathrm{C}\end{array}$ & $\begin{array}{c}\mathrm{mS} \mathrm{cm} \\
80{ }^{\circ} \mathrm{C}\end{array}$ \\
\hline $100: 0$ & 0 & 7.3 & 12.9 & 19.4 & 27.3 \\
\hline $90: 10$ & 0.3305 & 10.2 & 16.8 & 24.5 & 32.9 \\
\hline $80: 20$ & 0.5263 & 12.4 & 19.7 & 27.1 & 40.4 \\
\hline $70: 30$ & 0.6557 & 15.2 & 23.2 & 32.0 & 44.7 \\
\hline $60: 40$ & 0.7476 & 15.7 & 23.4 & 31.8 & 44.3 \\
\hline $50: 50$ & 0.8163 & 15.2 & 22.3 & 29.8 & 40.6 \\
\hline $40: 60$ & 0.8695 & 14.4 & 20.5 & 27.0 & 35.9 \\
\hline $30: 70$ & 0.9120 & 13.3 & 18.6 & 24.5 & 30.1 \\
\hline $20: 80$ & 0.9467 & $10.3^{a}$ & 14.2 & 18.4 & 22.9 \\
\hline $10: 90$ & 0.9756 & $6.2^{a}$ & 8.5 & 11.0 & 13.7 \\
\hline $0: 100$ & 1.0000 & $<0.01^{a}$ & $<0.01$ & $<0.01$ & $<0.01$ \\
\hline
\end{tabular}

${ }^{a}$ Data are received from supercooled liquid.

ionic liquid EMIM-TFSA, the ionic aggregates become more and more loosened which result in an increase in the ionic conductivity. This is in good accordance to the density, viscosity, and DSC data described before. The maximum temperature dependent conductivity value is received at EMIM-TFSA mole fraction of $\chi \approx 0.3$ (fraction $n(\mathrm{EC}) /$ $n($ EMIM-TFSA $)=2.4 ; n=$ amount of substance) which corresponds to weight ratios of 60:40 to 70:30 (EMIMTFSA:EC). At high EC concentrations $(\chi$ (EC) $>0.7$; $>40 \mathrm{wt}$ $\%$ EC), the molar conductivity value decrease rapidly. The different regimes are described for solvent-ionic liquid mixtures, namely, the neat ionic liquid regime, organic carbonate as dilute solvent, the IL as electrolyte in solution and pure organic solvent. ${ }^{20,43} \mathrm{EC}$ as a dipolar solvent is able to react closely with charged IL head groups as well as IL nonpolar domains. Its associating power allows it to form dipol-dipol and hydrogen bonds (IL-[H] to EC-[O]) to the ionic IL domains such that ion aggregation and correlated motion of EMIM-TFSA becomes reduced. ${ }^{20,43}$ Starting from pure EC, the 
a
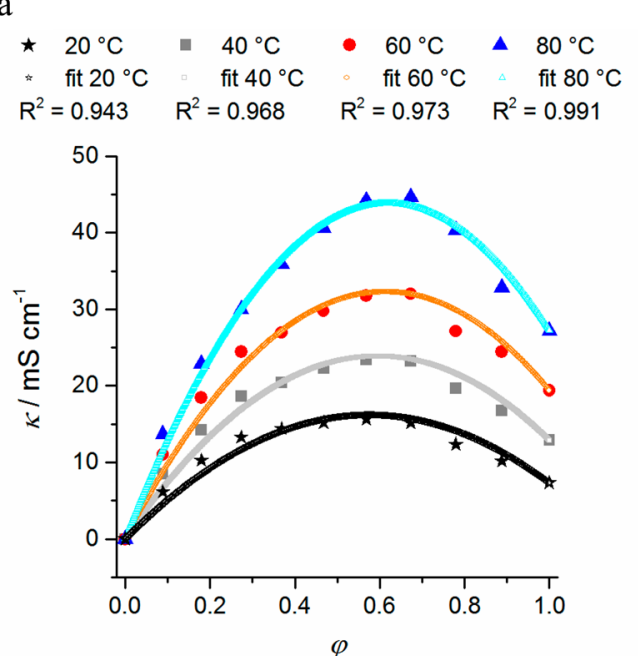

b

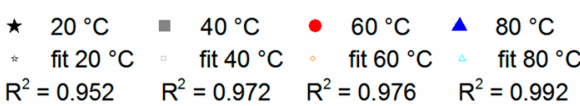

$R^{2}=0.972 \quad R^{2}=0.976 \quad R^{2}=0.992$

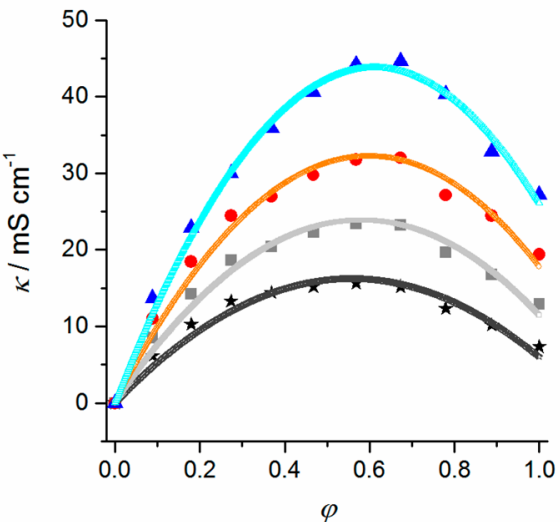

Figure 8. Conductivity versus volume fraction $\varphi$ of EMIM-TFSA; temperature-dependent fitting of conductivity according to lattice-hole theory with fixed $\kappa_{\text {IL }}$ (Figure 8a, according to eq 3) and as free $\kappa_{1}$ fitting (Figure 8b).
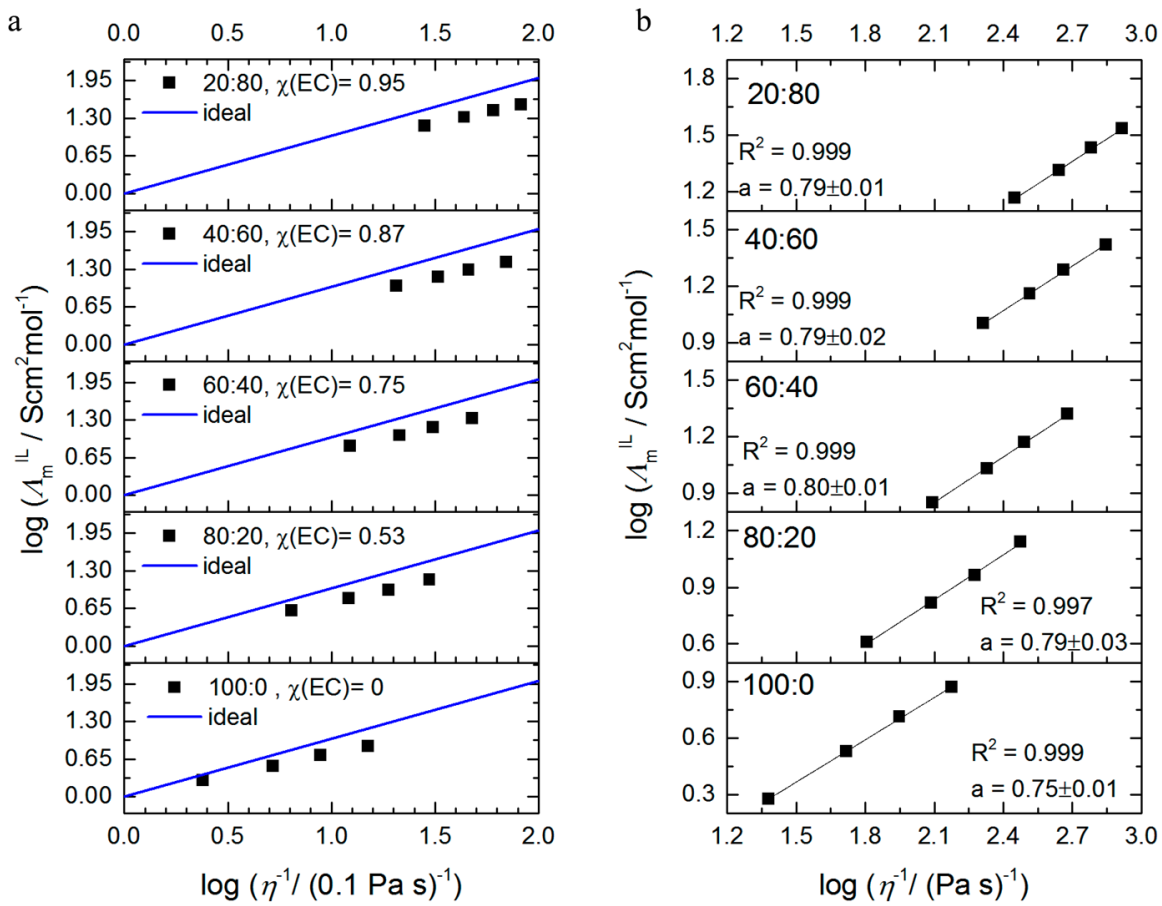

Figure 9. (a) Walden plots of temperature-dependent $\left(20-80^{\circ} \mathrm{C}\right)$ inverse viscosity and conductivity data of the mixtures $($ EMIM-TFSA/EC $=$ wt $/$ $\mathrm{wt})$. The results of the measurements are depicted as black squares, whereas the blue line displays the behavior of an ideal classical dilute aqueous solution (slope of 1). For a better comparison with plots in literature, the viscosity value is used in units of Poise (= $0.1 \mathrm{~Pa} \cdot \mathrm{s})$. (b) Walden plots of temperature-dependent $\left(20-80{ }^{\circ} \mathrm{C}\right)$ inverse viscosity and conductivity data of the mixtures. The results of the measurements are depicted as black squares, whereas the line displays the linear regression as mentioned besides $\left(a=\right.$ slope; $R^{2}=$ coefficient of determination).

ionic conductivity is very small at the beginning. The strong increase after adding small amounts of EMIM-TFSA (low $\chi$ (EMIM-TFSA) values) results from a typical salt in solvent behavior up to a maximum value. A further increase in the EMIM-TFSA concentration results in an increase in ion-ion interactions and ionic aggregates which reduce the ionic mobility as well as the ionic charge carriers. This leads to a reduction of the ionic conductivity value at high EMIM-TFSA concentrations.

The qualitative temperature dependency of the conductivity data of the mixtures is comparable to literature results for binary ionic liquid/organic solvent mixtures. ${ }^{14,15,20}$ In BMIM-
TFSA:PC mixtures, the temperature-dependent maximum value of the conductivity is obtained around $\chi_{\text {BMIM-TFSA }} \approx 0.2$ (fraction $n(\mathrm{PC}) / n($ BMIM-TFSA $)=3.8) .{ }^{14}$ Likewise the maximum of conductivity is obtained at $\chi_{\mathrm{BMIM}-\mathrm{BF} 4} \approx 0.18$ for $\mathrm{BMIM}^{-\mathrm{BF}_{4} / \mathrm{PC}^{15}}$

The conductivity of mixtures of ionic liquids and relatively small molecules which exhibit high relative permittivity can be fitted according to the lattice-hole theory (eq 3 ) where $\kappa$ is the conductivity, $\kappa_{\mathrm{IL}}$ is the pure ionic liquid conductivity, $\varphi$ the volume fraction, and $\kappa_{0}$ a fitting parameter which accounts for hydrodynamic and ionic atmosphere relaxation. ${ }^{44}$ Principally, the lattice-hole model presented by Woodward et al. is based 
upon a geometrically lattice model and can be used to evaluate the conductivity of a binary solvent/ionic liquid mixture. ${ }^{44} \mathrm{~A}$ better verification of the correlation can be achieved by using a second fitting parameter $\kappa_{1}$ instead of $\kappa_{\mathrm{IL}}$. In this manner, a comparison of the fitting value $\kappa_{1}$ and $\kappa_{\mathrm{IL}}$ can be seen as another proof of the lattice-hole concept.

$$
\kappa=(1-\varphi) \varphi \kappa_{0}+\varphi^{2} \kappa_{\mathrm{IL}}
$$

In this study, EC exhibits a dielectric constant at $40{ }^{\circ} \mathrm{C}$ of $\varepsilon_{\mathrm{r}}$ $=89.6$. Although the assumptions which were done during the derivation of eq 3 allow a qualitative description only, the data could be fitted with high accuracy. The results of the fittings according to eq 3 are depicted in Figure $8 \mathrm{a}$ where fitting values of $\kappa_{0}=56.3 \mathrm{mS} \cdot \mathrm{cm}^{-1}\left(20{ }^{\circ} \mathrm{C} ; u_{\mathrm{r}}\left(\kappa_{0}\right)=0.036 ; u(T)=0.05 \mathrm{~K}\right)$, $\kappa_{0}=80.2 \mathrm{mS} \cdot \mathrm{cm}^{-1}\left(40{ }^{\circ} \mathrm{C} ; u_{\mathrm{r}}\left(\kappa_{0}\right)=0.027 ; u(T)=0.05 \mathrm{~K}\right), \kappa_{0}=$ $105.4 \mathrm{mS} \cdot \mathrm{cm}^{-1}\left(60{ }^{\circ} \mathrm{C} ; u_{\mathrm{r}}\left(\kappa_{0}\right)=0.026 ; u(T)=0.05 \mathrm{~K}\right)$ and $\kappa_{0}=$ $141.7 \mathrm{mS} \cdot \mathrm{cm}^{-1}\left(80{ }^{\circ} \mathrm{C} ; u_{\mathrm{r}}\left(\kappa_{0}\right)=0.016 ; u(T)=0.05 \mathrm{~K}\right)$ are received. A free fitting procedure $\left(\kappa_{1}\right.$ as a parameter instead of $\left.\kappa_{\mathrm{IL}}\right)$ as described above leads to the following results: $\kappa_{0}=58.2$ $\mathrm{mS} \cdot \mathrm{cm}^{-1}, \kappa_{1}=6.0 \mathrm{mS} \cdot \mathrm{cm}^{-1}\left(20{ }^{\circ} \mathrm{C} ; u_{\mathrm{r}}\left(\kappa_{0}\right)=0.034 ; u_{\mathrm{r}}\left(\kappa_{1}\right)=\right.$ $0.13 ; u(T)=0.05 \mathrm{~K}) ; \kappa_{0}=82.3 \mathrm{mS} \cdot \mathrm{cm}^{-1}, \kappa_{1}=11.4 \mathrm{mS} \cdot \mathrm{cm}^{-1}$ $\left(40{ }^{\circ} \mathrm{C} ; u_{\mathrm{r}}\left(\kappa_{0}\right)=0.03 ; u_{\mathrm{r}}\left(\kappa_{1}\right)=0.079 ; u(T)=0.05 \mathrm{~K}\right) ; \kappa_{0}=$ $107.7 \mathrm{mS} \cdot \mathrm{cm}^{-1}, \kappa_{1}=17.8 \mathrm{mS} \cdot \mathrm{cm}^{-1}\left(60{ }^{\circ} \mathrm{C} ; u_{\mathrm{r}}\left(\kappa_{0}\right)=0.029\right.$; $\left.u_{\mathrm{r}}\left(\kappa_{1}\right)=0.067 ; u(T)=0.05 \mathrm{~K}\right) ; \kappa_{0}=143.3 \mathrm{mS} \cdot \mathrm{cm}^{-1}, \kappa_{1}=26.1$ $\mathrm{mS} \cdot \mathrm{cm}^{-1}\left(80{ }^{\circ} \mathrm{C} ; u_{\mathrm{r}}\left(\kappa_{0}\right)=0.017 ; u_{\mathrm{r}}\left(\kappa_{1}\right)=0.034 ; u(T)=0.05\right.$ $\mathrm{K})$. On the basis of these results, the calculated values of $\kappa_{1}$ (including the standard uncertainty of the fit value) are almost in the error range of the measured values of $\kappa_{\text {EMIM-TFSA. This }}$ demonstrates that the lattice-hole theory is valuable for the binary system EMIM-TFSA/EC and can be applied to the experimental data with high accuracy, even at higher temperatures. Compared to mixture BMIM-TFSA/PC, ${ }^{14}$ a much better correlation is obtained for the EMIM-TFSA/EC mixture which could be explained by a smaller molecular size and a higher dielectric constant of EC compared to PC.

Walden plots display the logarithm of molar ionic conductivity as a function of the logarithm of fluidity which is the inverse of viscosity (eq 4, Figure 9a). For linear fittings of binary mixtures, the limiting molar conductivity $\Lambda_{\mathrm{m}}{ }^{0}$ was replaced by the molar conductivity $\Lambda_{\mathrm{m}}{ }^{\mathrm{IL}}$, which consists of the amount of substance of the ionic liquid EMIM-TFSA $n_{\mathrm{IL}}$ to the total molar conductivity. ${ }^{13}$ Accordingly, the ionic molar conductivity $\Lambda_{\mathrm{m}}^{\mathrm{IL}}$ is composed of the temperature-dependent specific conductivity $\kappa$, the temperature-dependent density $d$ of the mixture, and the total mass $m$ (eq 5 ).

$$
\begin{aligned}
& \log \Lambda_{m}^{0}=\log C^{\prime}+a \log \eta^{-1} \\
& \Lambda_{m}^{\mathrm{IL}}=\frac{\kappa}{\left(\frac{m_{\mathrm{LL}}}{M_{\mathrm{LL}}}\right) \frac{d}{m}}
\end{aligned}
$$

The fittings are plotted in Figure 9b and suggest an almost identical slope of $a=0.79$ for the mixtures $\left(R^{2}>0.997\right.$; slope of pure EMIM-TFSA $a=0.75 ; u(a)=0.015 \cdot a$ ). Deviations from the ideal line for classical dilute aqueous solutions (depicted in blue color in Figure 9a) are caused by correlations between the molecules/ions which result in different contributions to viscosity and conductivity. ${ }^{7,38,45}$ Here, the concept of ionicity was introduced to quantify such deviations from the ideal behavior. ${ }^{7,46}$ The pure ionic liquid EMIM-TFSA is close to the ideal line in accordance to literature results of ionic liquids. ${ }^{7,30,38,47,48}$ This led to the assumption that each ion in EMIM-TFSA is close to equally influenced by all of its neighbors and isolated ion pairing between anions and cations does not occur.

It is observed that negative deviations $\Delta$, from the ideal line arise with increasing EC content in the mixture. Thus, stronger correlations, which influence either viscosity or conductivity, exist in the mixtures. This is also supported by comparing conductivity and viscosity data (Figure 10). With an increase of

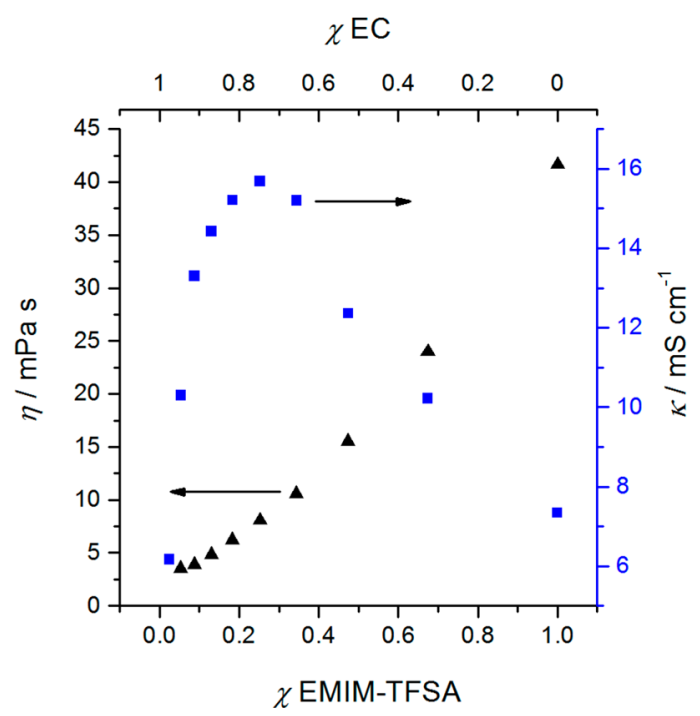

Figure 10. Correlation between conductivity (blue, squares) and viscosity data (black, triangle) at $20{ }^{\circ} \mathrm{C}$ is depicted for comparison.

the EC content, EC molecules can segregate the complex EMIM-TFSA structure which results in smaller and more isolated $\left[\mathrm{EMIM}^{+}\right]\left[\mathrm{TFSA}^{-}\right]$ion pairing, and the viscosity of the mixture declines. A second effect, which influences the conductivity and causes a negative deviation $\Delta$ with respect to the ideal line in the Walden plot, is the attenuation of the external electric field by charged ionic species inside the solvent. ${ }^{7}$ This effect is even more pronounced if the concentration of the ionic species is high (at high mole fractions of EMIM-TFSA). Thus, at least two contrasting effects result in the deviation from the ideal line in the Walden plot.

\section{CONCLUSION}

This study presents temperature-dependent data of conductivity, viscosity, and density of the binary mixtures composed of EMIM-TFSA and EC. Additionally, DSC measurements are performed for evaluating the phase behavior of the mixtures in a temperature range of $(-150$ to +100$){ }^{\circ} \mathrm{C}$. It is shown that the mixtures can be classified as fragile according to the fragility concept. The lattice hole theory can be used to fit temperaturedependent conductivity data of binary EMIM-TFSA/EC mixtures with high accuracy. It could be shown that the addition of ethylene carbonate to the ionic liquid EMIM-TFSA causes the segregation of EMIM-TFSA ionic aggregates which influences the physicochemical behavior of such mixtures. The data can be used as experimental proof for theoretical calculations of molecular structures and should be a helpful data set for applications in electrochemical and physicochemical approaches. 


\section{ASSOCIATED CONTENT}

\section{S Supporting Information}

The Supporting Information is available free of charge on the ACS Publications website at DOI: 10.1021/acs.jced.5b00338.

DSC data of additional EMIM-TFSA/EC mixtures; DSC measurement of EMIM-TFSA in closed $\mathrm{Al}$ crucible from $-150{ }^{\circ} \mathrm{C}$ to $100{ }^{\circ} \mathrm{C}$ at $5 \mathrm{~K} \mathrm{~min}^{-1}$ (exo down) without annealing before the measurement (PDF)

\section{AUTHOR INFORMATION}

\section{Corresponding Author}

*Tel.: +49 (0)721-608-25920. Fax: +49 (0)721-608-22095. Email: andreas.hofmann2@kit.edu.

\section{Funding}

A.H. acknowledges support by Deutsche Forschungsgemeinschaft (Sachbeihilfe, HO 5266/1-1).

Notes

The authors declare no competing financial interest.

\section{ACKNOWLEDGMENTS}

We acknowledge Iolitec for providing EMIM-TFSA.

\section{REFERENCES}

(1) Krossing, I.; Slattery, J. M.; Daguenet, C.; Dyson, P. J.; Oleinikova, A.; Weingartner, $\mathrm{H}$. Why are ionic liquids liquid? A simple explanation based on lattice and solvation energies. J. Am. Chem. Soc. 2006, 128, 13427-13434.

(2) Galinski, M.; Lewandowski, A.; Stepniak, I. Ionic liquids as electrolytes. Electrochim. Acta 2006, 51, 5567-5580.

(3) Holbrey, J. D.; Seddon, K. R. Ionic Liquids. Clean Technol. Environ. Policy 1999, 1, 223-236.

(4) Werner, S.; Haumann, M.; Wasserscheid, P. Ionic Liquids in Chemical Engineering. Annu. Rev. Chem. Biomol. Eng. 2010, 1, $203-$ 230.

(5) Singh, G.; Kumar, A. Ionic liquids: Physico-chemical, solvent properties and their applications in chemical processes. Indian J. Chem. 2008, 47A, 495-503.

(6) Seki, S.; Kawano, R.; Watanabe, M. Ionic liquids and clean energy conversion and storage. Kag. Kog. 2006, 59 (7), 760-763.

(7) MacFarlane, D. R; Forsyth, M.; Izgorodina, E. I.; Abbott, A. P.; Annat, G.; Fraser, K. On the concept of ionicity in ionic liquids. Phys. Chem. Chem. Phys. 2009, 11, $4962-4967$.

(8) MacFarlane, D. R.; Pringle, J. M.; Howlett, P. C.; Forsyth, M. Ionic liquids and reactions at the electrochemical interface. Phys. Chem. Chem. Phys. 2010, 12, 1659.

(9) Wilken, S.; Xiong, S.; Scheers, J.; Jacobsson, P.; Johansson, P. Ionic liquids in lithium battery electrolytes: Composition versus safety and physical properties. J. Power Sources 2015, 275, 935-942.

(10) Yang, B.; Li, C.; Zhou, J.; Liu, J.; Zhang, Q. Pyrrolidinium-based ionic liquid electrolyte with organic additive and LiTFSI for high-safety lithium-ion batteries. Electrochim. Acta 2014, 148, 39-45.

(11) Pohlmann, S.; Olyschläger, T.; Goodrich, P.; Vicente, J. A.; Jacquemin, J.; Balducci, A. Mixtures of Azepanium Based Ionic Liquids and Propylene Carbonate as High Voltage Electrolytes for Supercapacitors. Electrochim. Acta 2015, 153, 426-432.

(12) Indris, S.; Heinzmann, R.; Schulz, M.; Hofmann, A. Ionic Liquid Based Electrolytes: Correlating Li Diffusion Coefficients and Battery Performance. J. Electrochem. Soc. 2014, 161, A2036-A2041.

(13) Hofmann, A.; Schulz, M.; Hanemann, T. Effect of Conducting Salts in Ionic Liquid based Electrolytes: Viscosity, Conductivity, and Li-Ion Cell Testing. Int. J. Electrochem. Sci. 2013, 8, 10170-10189.

(14) Vraneš, M.; Zec, N.; Tot, A.; Papović, S.; Dožić, S.; Gadžurić, S. Density, electrical conductivity, viscosity and excess properties of 1butyl-3-methylimidazolium bis(trifluoromethylsulfonyl)imide and pro- pylene carbonate binary mixtures. J. Chem. Thermodyn. 2014, 68, 98108.

(15) Stoppa, A.; Hunger, J.; Buchner, R. Conductivities of Binary Mixtures of Ionic Liquids with Polar Solvents. J. Chem. Eng. Data 2009, 54, 472-479.

(16) Le, M. L. P.; Cointeaux, L.; Strobel, P.; Leprêtre, J.-C.; Judeinstein, P.; Alloin, F. Influence of Solvent Addition on the Properties of Ionic Liquids. J. Phys. Chem. C 2012, 116, 7712-7718.

(17) Geppert-Rybczyńska, M.; Heintz, A.; Lehmann, J. K.; Golus, A. Volumetric Properties of Binary Mixtures Containing Ionic Liquids and Some Aprotic Solvents. J. Chem. Eng. Data 2010, 55, 4114-4120.

(18) Kühnel, R.-S.; Balducci, A. Lithium Ion Transport and Solvation inN-Butyl-N-methylpyrrolidinium Bis(trifluoromethanesulfonyl)imide-Propylene Carbonate Mixtures. J. Phys. Chem. C 2014, 118, $5742-5748$

(19) Kühnel, R. S.; Böckenfeld, N.; Passerini, S.; Winter, M.; Balducci, A. Mixtures of ionic liquid and organic carbonate as electrolyte with improved safety and performance for rechargeable lithium batteries. Electrochim. Acta 2011, 56, 4092-4099.

(20) Fox, E. T.; Paillard, E.; Borodin, O.; Henderson, W. A. Physicochemical Properties of Binary Ionic Liquid-Aprotic Solvent Electrolyte Mixtures. J. Phys. Chem. C 2013, 117, 78-84.

(21) Pereiro, A. B.; Tojo, E.; Rodríguez, A.; Canosa, J.; Tojo, J. Properties of ionic liquid HMIMPF6 with carbonates, ketones and alkyl acetates. J. Chem. Thermodyn. 2006, 38, 651-661.

(22) McEwen, A. B.; Ngo, H. L.; LeCompte, K.; Goldman, J. L. Electrochemical Properties of Imidazolium Salt Electrolytes for Electrochemical Capacitor Applications. J. Electrochem. Soc. 1999, $146,1687-1695$.

(23) Borodin, O.; Henderson, W. A.; Fox, E. T.; Berman, M.; Gobet, M.; Greenbaum, S. Influence of Solvent on Ion Aggregation and Transport in PY15TFSI Ionic Liquid-Aprotic Solvent Mixtures. J. Phys. Chem. B 2013, 117, 10581-10588.

(24) Wilson, G. J.; Hollenkamp, A. F.; Pandolfo, A. G. Resolving Ambiguous Naming for an Ionic Liquid Anion. Chem. Int. 2007, 29, $16-18$.

(25) Matsumoto, H.; Yanagida, M.; Tanimoto, K.; Nomura, M.; Kitagawa, Y.; Miyazaki, Y. Highly Conductive Room Temperature Molten Salts Based on Small Trimethylalkylammonium Cations and Bis(trifluoromethylsulfonyl)imide. Chem. Lett. 2000, 29, 922-923.

(26) Noack, K.; Schulz, P. S.; Paape, N.; Kiefer, J.; Wasserscheid, P.; Leipertz, A. The role of the $\mathrm{C} 2$ position in interionic interactions of imidazolium based ionic liquids: a vibrational and NMR spectroscopic study. Phys. Chem. Chem. Phys. 2010, 12, 14153.

(27) Fredlake, C. P.; Crosthwaite, J. M.; Hert, D. G.; Aki, S. N. V. K.; Brennecke, J. F. Thermophysical Properties of Imidazolium-Based Ionic Liquids. J. Chem. Eng. Data 2004, 49, 954-964.

(28) Geppert-Rybczyńska, M.; Heintz, A.; Lehmann, J. K.; Golus, A. Volumetric Properties of Binary Mixtures Containing Ionic Liquids and Some Aprotic Solvents. J. Chem. Eng. Data 2010, 55, 4114-4120.

(29) Widegren, J. A.; Saurer, E. M.; Marsh, K. N.; Magee, J. W. Electrolytic conductivity of four imidazolium-based room-temperature ionic liquids and the effect of a water impurity. J. Chem. Thermodyn. 2005, 37, 569-575.

(30) Schreiner, C.; Zugmann, S.; Hartl, R.; Gores, H. J. Fractional Walden Rule for Ionic Liquids: Examples from Recent Measurements and a Critique of the So-Called Ideal $\mathrm{KCl}$ Line for the Walden Plot $\dagger$. J. Chem. Eng. Data 2009, 55, 1784-1788.

(31) Shiflett, M. B.; Harmer, M. A.; Junk, C. P.; Yokozeki, A. Solubility and Diffusivity of Difluoromethane in Room-Temperature Ionic Liquids. J. Chem. Eng. Data 2006, 51, 483-495.

(32) Morita, M.; Asai, Y.; Yoshimoto, N.; Ishikawa, M. A Raman spectroscopic study of organic electrolyte solutions based on binary solvent systems of ethylene carbonate with low viscosity solvents which dissolve different lithium salts. J. Chem. Soc., Faraday Trans. 1998, 94, 3451-3456.

(33) Lehmann, J.; Rausch, M. H.; Leipertz, A.; Fröba, A. P. Densities and Excess Molar Volumes for Binary Mixtures of Ionic Liquid 1- 
Ethyl-3-methylimidazolium Ethylsulfate with Solvents. J. Chem. Eng. Data 2010, 55, 4068-4074.

(34) Paulechka, Y. U.; Blokhin, A. V.; Kabo, G. J.; Strechan, A. A. Thermodynamic properties and polymorphism of 1-alkyl-3-methylimidazolium bis(triflamides). J. Chem. Thermodyn. 2007, 39, 866-877.

(35) Vogel, H. Phys. Z. 1921, 22, 645.

(36) Fulcher, G. S. J. Am. Ceram. Soc. 1925, 8, 339.

(37) Tammann, G.; Hesse, W. Z. Anorg. Allg. Chem. 1926, 156, 245.

(38) Xu, W.; Cooper, E. I.; Angell, C. A. Ionic Liquids: Ion Mobilities, Glass Temperatures, and Fragilities. J. Phys. Chem. B 2003, 107, 6170-6178.

(39) Angell, C. A. Liquid Fragility and the Glass Transition in Water and Aqueous Solutions. Chem. Rev. 2002, 102, 2627-2650.

(40) Nascimento, M. L. F.; Aparicio, C. Data classification with the Vogel-Fulcher-Tammann-Hesse viscosity equation using correspondence analysis. Phys. B 2007, 398, 71-77.

(41) Harris, K. R.; Kanakubo, M.; Woolf, L. A. Temperature and Pressure Dependence of the Viscosity of the Ionic Liquids 1-Hexyl-3methylimidazolium Hexafluorophosphate and 1-Butyl-3-methylimidazolium Bis(trifluoromethylsulfonyl)imide. J. Chem. Eng. Data 2007, 52, $1080-1085$

(42) Martinelli, A.; Matic, A.; Jacobsson, P.; Börjesson, L.; Fernicola, A.; Scrosati, B. Phase Behavior and Ionic Conductivity in Lithium Bis(trifluoromethanesulfonyl)imide-Doped Ionic Liquids of the Pyrrolidinium Cation and Bis(trifluoromethanesulfonyl)imide Anion. J. Phys. Chem. B 2009, 113, 11247-11251.

(43) Pádua, A. A. H.; Costa Gomes, M. F.; Canongia Lopes, J. N. A. Molecular Solutes in Ionic Liquids: A Structural Perspective. Acc. Chem. Res. 2007, 40, 1087-1096.

(44) Woodward, C. E.; Harris, K. R. A lattice-hole theory for conductivity in ionic liquid mixtures: application to ionic liquid + water mixtures. Phys. Chem. Chem. Phys. 2010, 12, 1172-1176.

(45) Austen Angell, C.; Ansari, Y.; Zhao, Z. Ionic Liquids: Past, present and future. Faraday Discuss. 2012, 154, 9.

(46) Ueno, K.; Tokuda, H.; Watanabe, M. Ionicity in ionic liquids: correlation with ionic structure and physicochemical properties. Phys. Chem. Chem. Phys. 2010, 12, 1649-1658.

(47) Sanchez-Ramirez, N.; Martins, V. L.; Ando, R. A.; Camilo, F. F.; Urahata, S. M.; Ribeiro, M. C. C.; Torresi, R. M. Physicochemical Properties of Three Ionic Liquids Containing a Tetracyanoborate Anion and Their Lithium Salt Mixtures. J. Phys. Chem. B 2014, 118, $8772-8781$.

(48) Schreiner, C.; Zugmann, S.; Hartl, R.; Gores, H. J. Temperature Dependence of Viscosity and Specific Conductivity of FluoroborateBased Ionic Liquids in Light of the Fractional Walden Rule and Angell's Fragility Concept. J. Chem. Eng. Data 2010, 55, 4372-4377. 